\title{
Assessment of local technogenic hazards of the industrial zone
}

\author{
Oleg Denisov ${ }^{1, *}$, Alex Ponomarev ${ }^{1}$, Irina Ponomareva ${ }^{2}$, and Viktoria Stadnik ${ }^{3}$ \\ ${ }^{1}$ Don State Technical University, Rostov-on-Don, Russian Federation \\ ${ }^{2}$ Southern Federal University, Rostov-on-Don, Russian Federation \\ ${ }^{3}$ Far Eastern Federal University, Vladivostok, Russian Federation
}

\begin{abstract}
The article deals with the issues of employee safety under the influence of local man-made hazards. The example of the welding process is used to calculate the risk of work in a confined space. The issues of application of protective means for prevention of violations of health of the worker are discussed.The situation of emergency shutdown of ventilation during the work of personnel in difficult conditions was simulated. When calculating the probability of risk occurrence in the simulated situation, toxic effects of nitrogen dioxide on the health were established for the options of absence and presence of protection (mask).
\end{abstract}

\section{Relevance and statement of a problem}

Industrial and construction manufacture in big cities is characterized by a significant amount of local technogenic hazards. There are more than 60 types of technological processes, such as welding, thermal cutting and surfacing of metal. The quantitative and qualitative value of local technogenic hazards depends on the conditions and structure of manufacturing. In the quantification of hazards associated, for example, with welding, the compound of the released substances during this process matters $[1,2]$.

Analysis of modern technological processes has shown that the most effective productive methods are used in most industrial areas. It includes arc welding, which is quite affordable, economical and common technology used in various spheres of industrial in big cities. When performing this kind of work, harmful and dangerous aerosols, a large number of which are characteristic of manual arc welding, are released into the breathing zone of manufacturing personnel in the absence of effective filter-ventilation installations [2-4]. Medical studies indicate that such local technogenic hazards are one of the main causes of occupational diseases. The most harmful aerosol emissions include oxides of manganese, titanium, silicon, chromium, aluminum, tungsten, iron, vanadium, zinc, copper, Nickel and other elements. The most harmful gases released during welding and cutting are nitrogen oxides (especially nitrogen dioxide), carbon monoxide, ozone, hydrogen fluoride [5].

From the point of view of labor legislation of many countries, working conditions of welders are recognized as unfavorable for health [6]. The implementation of professional risk assessment is fixed by regulatory acts. According to modern researchers, a detailed

* Corresponding author: OVD63@mail.ru 
study of the occupational risk management system in the conditions of local technogenic hazards is a highly effective mechanism for ensuring safe working conditions $[7,8]$. Analysis of scientific calculations and practical research shows that the optimal ventilation combined with a complex of organizational and technical nature may cause a decrease in the concentration of harmful and hazardous substances to the maximum permissible values and contributes to improving the working conditions of staff when working in difficult conditions. Meanwhile, despite the development of modern technologies, the welding process in terms of reducing emissions is currently not optimal, and in the conditions of emergency ventilation shutdown can cause an accident [9].

\section{Discussion and results}

The aim of this study was to assess the probability of local technogenic hazards on the example of the study damage for health and death in the implementation of welding operations in difficult manufacture conditions.

Research problem:

1. To construct a linguistic model for the implementation of the damage in a simulated emergency (failure of the ventilation system in the implementation of welding in the tank).

2. Determine the existing prerequisites and build a logical-parametric model for the implementation of the damage.

3. A calculated method to determine the probability of the first damage (toxic effect disease) and the second damage (toxic effect - death) in a simulated emergency (ventilation system failure).

For the prototype of the event, an emergency shutdown of the ventilation system in the implementation of welding works in the tank is conventionally accepted. The volume of the tank is $16 \mathrm{~m} 3$. To carry out the calculations, a cycle of directly welder («clean») work in a container with a duration of 1 hour 30 minutes, the consumption of electrodes $-2 \mathrm{~kg}$ is conventionally taken.

The amount of released harmful impurities of the i-th component in manual arc welding per $1 \mathrm{~kg}$ of consumed electrodes is determined by the formula:

$$
\mathrm{Gi}=\mathrm{gi} * \mathrm{~B},
$$

where gi - is a specific i-component isolation per $1 \mathrm{~kg}$ of consumed electrodes (table 1); $\mathrm{B}-$ is a mass of consumable electrodes during the period under consideration.

Table 1. The specific selection of contaminants for manual welding electrodes.

Type UONI 13/55 per $1 \mathrm{~kg}$ of spent electrodes.

\begin{tabular}{|c|c|c|c|c|c|c|}
\hline \multicolumn{7}{|c|}{ The name and the specific amount of emitted pollutants } \\
\cline { 2 - 6 } $\begin{array}{c}\text { welding } \\
\text { aerosol }\end{array}$ & iron oxide & $\begin{array}{c}\text { manganese } \\
\text { and its } \\
\text { compounds }\end{array}$ & $\begin{array}{c}\text { inorganic dust } \\
\text { containing } \mathrm{SiO}_{2} \\
20-70 \%\end{array}$ & $\begin{array}{c}\text { hydrogen } \\
\text { fluoride }\end{array}$ & $\begin{array}{c}\text { nitrogen } \\
\text { dioxide }\end{array}$ & $\begin{array}{c}\text { carbon } \\
\text { monoxide }\end{array}$ \\
\hline 16.99 & 14.90 & 1.09 & 1.00 & 0.930 & 2.70 & 13.30 \\
\hline
\end{tabular}

After obtaining the amount of impurities released into the air during welding and calculating the volume of the container, the concentration of substances in the air $(\mathrm{mg} / \mathrm{m} 3)$ is calculated):

$$
\mathrm{C}=\mathrm{G} * 103 / \mathrm{V}
$$


where $\mathrm{G}$ - is the amount of released harmful impurities of the $\mathrm{i}$-th component, $\mathrm{V}$ - is the volume of the tank, $\mathrm{m} 3$.

Calculation of the probability of the damage «disease» and damage «death» in simulated conditions with the use of protection (gas mask) and without it (on the basis of recommendations [7, 10-17]).

When calculating the concentration in the air of the working area (capacity $-16 \mathrm{~m} 3$ ) substances released within 1 hour 30 minutes at a flow rate of electrodes $2 \mathrm{~kg}$, the following values (table 2).

Table 2. Concentration of substances in the air obtained by calculation method, $\mathrm{mg} / \mathrm{m}^{3}$

\begin{tabular}{|c|c|c|c|c|}
\hline iron oxide & $\begin{array}{c}\text { manganese and its } \\
\text { compounds }\end{array}$ & hydrogen fluoride & $\begin{array}{c}\text { nitrogen } \\
\text { dioxide }\end{array}$ & carbon oxide \\
\hline 1862.5 & 136.25 & 116.25 & 337.5 & 1662.5 \\
\hline
\end{tabular}

Model of realization of the damage and calculation of risks, linguistic model of the implementation of damage:

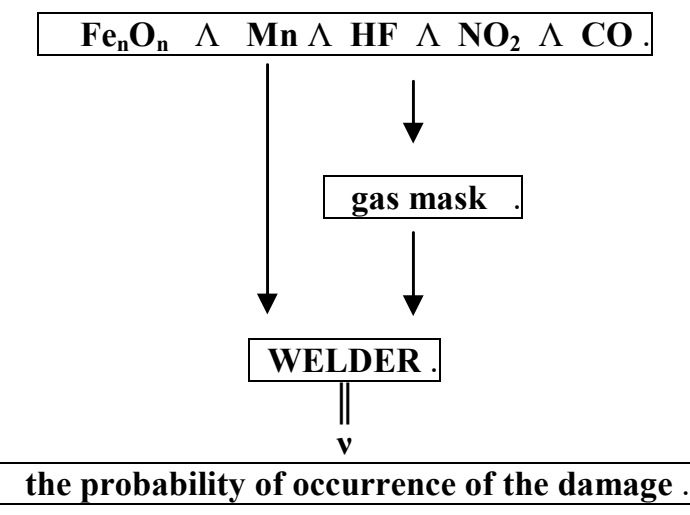

Fig. 1. The model of realization of the damage and calculation of risks.

Logical-parametric model (with prerequisites):

Suppose that when exposed to human (welder) harmful and dangerous factors (harmful components of welding aerosol - manganese and its oxides, iron oxide, hydrogen fluoride, nitrogen dioxide and carbon monoxide), possible damages are disease (the first damage) and death (the second damage). In this case, the impact will be both direct (without protection) and weakened personal protective equipment - a gas mask.

In this case, for MPE (maximum permissible exposure) take for iron oxide- $89.5 \mathrm{mg} / \mathrm{m} 3$ (the minimum dose described in the literature, which caused the «iron fever» welder), for manganese and its compounds $2.3 \mathrm{mg} / \mathrm{m} 3$ (the lowest published toxic dose), for hydrogen fluoride $-8 \mathrm{mg} / \mathrm{m} 3$ (threshold of irritant action), for nitrogen dioxide $-3.8 \mathrm{mg} / \mathrm{m} 3$ (the minimum dose described in the literature, which caused and for carbon monoxide -600 $\mathrm{mg} / \mathrm{m} 3$ (observed clinical manifestations when working for 2 hours). There is no CEL (critical exposure limit) for iron oxide because there is no description of any fatal event for any duration of exposure and any concentration of iron oxide per person. For CEL for manganese and its compounds, we will take $500 \mathrm{mg} / \mathrm{m} 3$ (instantly-life-or health-threatening concentration) due to the fact that the emergency exposure limit in the air $(5 \mathrm{mg} / \mathrm{m} 3)$ is set for continuous stay in the considered zone for at least 8 hours, and our experiment is limited to a cycle of 1 hour 30 minutes of «clean» work. For the CEL of hydrogen fluoride, we take $1500 \mathrm{mg} / \mathrm{m} 3$ (the described concentration, the effect of which within 5 minutes leads to 
death), for the CEL of nitrogen dioxide - $37.6 \mathrm{mg} / \mathrm{m} 3$, and carbon monoxide - $3400 \mathrm{mg} / \mathrm{m} 3$ (the minimum concentration described in the literature that caused the lethal outcome) $[5,9$, 18-30].

Let's make a logical (Boolean) function of the incident:

$\mathrm{y}=\mathrm{y} 1 \vee \mathrm{y} 2 ; \quad \mathrm{y} 1=\mathrm{x} 1 \vee \mathrm{x} 2 \vee \mathrm{x} 3 \vee \mathrm{x} 4 \vee \mathrm{x} 5 ; \quad \mathrm{y} 2=\mathrm{x} 1 \vee \mathrm{x} 2 \vee \mathrm{x} 3 \vee \mathrm{x} 5$,

where $y 1$ - the probability of occurrence of the damage «disease», $y 2$ - the probability of occurrence of the damage «death», $x 1$ - the probability of occurrence of the damage from exposure to iron oxide, $\mathrm{x} 2$ - the probability of occurrence of the damage from exposure to manganese and its compounds, $\mathrm{x} 3$ - the probability of occurrence of the damage from exposure to hydrogen fluoride and $\mathrm{x} 4$ - the probability of occurrence of the damage from exposure to nitrogen dioxide, $x 5$ - the probability of occurrence of the damage from the effects on the body of carbon monoxide.

We transform the logical (Boolean) function of the incident into the probabilistic form:

Provided $\quad \mathrm{S} 1 \geq \operatorname{MPE} 1, \operatorname{Pro1}(\mathrm{x} 1=1)=\mathrm{p} 1, \quad \mathrm{~S} 2 \geq \operatorname{MPE} 2, \operatorname{Pro} 2(\mathrm{x} 2=1)=\mathrm{p} 2$,

$$
\begin{aligned}
& \text { S3 } \geq \operatorname{MPE} 3, \operatorname{Pro} 3(x 3=1)=p 3, \quad \text { S4 } \geq \operatorname{MPE} 4, \operatorname{Pro} 4(x 4=1)=p 4, \\
& \text { S5 } \geq \operatorname{MPE} 5, \operatorname{Pro5}(x 5=1)=p 5,
\end{aligned}
$$

where S1 - criterion parametric effects (for the onset of the damage when exposed to iron oxide), S2 - criterion parametric effects (for the onset of the damage when exposed to manganese and its compounds) S3 - criterion parametric effects (for the onset of the damage when exposed to hydrogen fluoride), S4 - criterion parametric effects (for the onset of the damage when exposed to nitrogen dioxide), S5 - criterion of parametric influence (for the occurrence of damage under the influence of carbon monoxide), p1, p2, p3, p4 and p5 - real variables - probability of outcomes.

The operation of logical addition (disjunction) of two variables of the form:

$$
\mathrm{x} 1 v \mathrm{x} 2 v \mathrm{x} 3 v \mathrm{x} 4, \quad \mathrm{P} 1=\operatorname{Pro}(\mathrm{y} 1=1)
$$

is replaced by the operation of the form:

$$
\mathrm{P} 1=1-(1-\mathrm{p} 1) *(1-\mathrm{p} 2) *(1-\mathrm{p} 3) *(1-\mathrm{p} 4) *(1-\mathrm{p} 5),
$$

a logical addition operation of the form:

$$
\mathrm{y} 2=\mathrm{x} 1 v \mathrm{x} 2 v \mathrm{x} 3 v \mathrm{x} 5, \mathrm{P} 2=\operatorname{Pro}(\mathrm{y} 2=1)
$$

is replaced by an operation of the form:

$$
\mathrm{P} 1=1-(1-\mathrm{p} 1) *(1-\mathrm{p} 2) *(1-\mathrm{p} 3) *(1-\mathrm{p} 5) .
$$

Option 1:

Calculation of the probability of the first damage (disease): protection (gas mask) is absent (attenuation function $\mathrm{f}=1$ ). We calculate the parametric safety margin ( $\mathrm{U}$ ) and express through it the $\mathrm{p}$ - real variables - probabilities of outcomes:

$$
\begin{gathered}
\mathrm{U} 1=(\mathrm{S} 1-\mathrm{MPE} 1) /(\mathrm{S} 12+\mathrm{r} 2) 0.5, \quad \mathrm{U} 2=(\mathrm{S} 2-\mathrm{MPE} 2) /(\mathrm{S} 22+\mathrm{r} 2) 0.5, \\
\mathrm{U} 3=(\mathrm{S} 3-\mathrm{MPE} 3) /(\mathrm{S} 32+\mathrm{r} 2) 0.5, \quad \mathrm{U} 4=(\mathrm{S} 4-\mathrm{MPE} \mathrm{B} 4) /(\mathrm{S} 42+\mathrm{r} 2) 0.5, \\
\mathrm{U} 5=(\mathrm{S} 5-\mathrm{MPE} 5) /(\mathrm{S} 52+\mathrm{r} 2) 0.5,
\end{gathered}
$$


where S1 - criterion parametric effects (for the onset of the damage when exposed to iron oxide), MPE1 - 89,5; S2 - criterion parametric effects (for the onset of the damage when exposed to manganese and its compounds), MPE2 - 2,3; S3 - criterion parametric effects (for the onset of the damage when exposed to hydrogen fluoride), MPE3 - 8; S4 criterion parametric effects (for the onset of the damage when exposed to nitrogen dioxide), MPE4 - 3,8; S5 - criterion parametric effects (for the onset of the damage when exposed to carbon monoxide), MPE5 - 600; $\mathrm{r}$ - perception (take for $0.5^{*} \mathrm{MPE}$ ).

Table 3. The probability of occurrence of a damage «disease» from the action of welding aerosol substances (manganese and its compounds or hydrogen fluoride or nitrogen dioxide or iron oxide or carbon monoxide) in the absence of protection (gas mask).

\begin{tabular}{|c|c|c|c|c|}
\hline iron oxide & $\begin{array}{c}\text { manganese and its } \\
\text { compounds }\end{array}$ & hydrogen fluoride & nitrogen dioxide & carbon oxide \\
\hline 0.951946274 & 0.983112646 & 0.931174183 & 0.988739656 & 0.639097715 \\
\hline
\end{tabular}

$$
P=1-\left(1-p_{1}\right) *\left(1-p_{2}\right) *\left(1-p_{3}\right) *\left(1-p_{4}\right) *\left(1-p_{5}\right)=0.999999773
$$

Conclusion on option 1: the probability of disease from the action of welding aerosol substances (iron oxide, or manganese and its compounds, or hydrogen fluoride, or nitrogen dioxide, or carbon monoxide) in the absence of protection (gas mask) by the end of the working cycle ( 1 hour 30 minutes of the work) is $\approx 99.9 \%$ (Fig. 2 ).

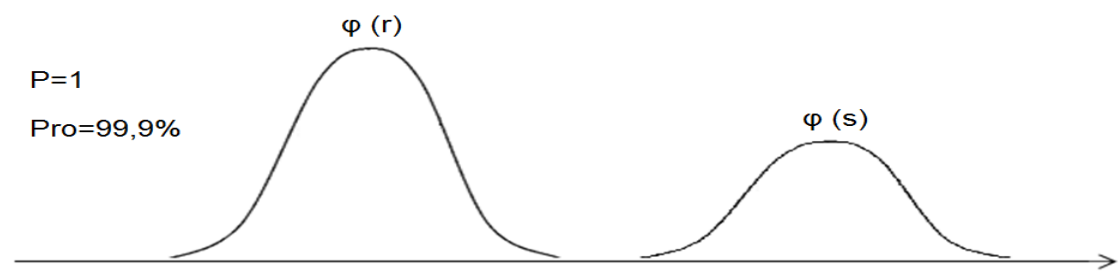

Fig. 2. The first damage in the absence of protection.

Option 2:

The calculation of the probability of the first damage (disease): availability protection (mask), the function of weakening $\mathrm{f}=0,05$. We calculate the parametric safety margin (U) and express through it the $\mathrm{p}$ - real variables - probabilities of outcomes:

$$
\begin{gathered}
\mathrm{U} 1=(\mathrm{f} * \mathrm{~S} 1-\mathrm{MPE} 1) /((\mathrm{f} * \mathrm{~S} 1) 2+\mathrm{r} 2) 0.5, \quad \mathrm{U} 2=(\mathrm{f} * \mathrm{~S} 2-\mathrm{MPE} 2) /((\mathrm{f} * \mathrm{~S} 2) 2+\mathrm{r} 2) 0.5, \\
\mathrm{U} 3=(\mathrm{f} * \mathrm{~S} 3-\mathrm{MPE} 3) /((\mathrm{f} * \mathrm{~S} 3) 2+\mathrm{r} 2) 0.5, \quad \mathrm{U} 4=(\mathrm{f} * \mathrm{~S} 4-\mathrm{MPE} 4) /((\mathrm{f} * \mathrm{~S} 4) 2+\mathrm{r} 2) 0.5, \\
\mathrm{U} 5=(\mathrm{S} 5-\mathrm{MPE} 5) /(\mathrm{S} 52+\mathrm{r} 2) 0.5,
\end{gathered}
$$

where S1 - criterion parametric effects (for the onset of the damage when exposed to iron oxide), MPE1 - 89.5; S2 - criterion parametric effects (for the onset of the damage when exposed to manganese and its compounds), MPE2 - 2.3; S3 - criterion parametric effects (for the onset of the damage when exposed to hydrogen fluoride), MPE3 - 8; S4 criterion parametric effects (for the onset of the damage when exposed to nitrogen dioxide), MPE4 - 3.8; S5 - criterion parametric effects (for the onset of the damage when exposed to carbon monoxide), MPE5 - 600; $\mathrm{r}$ - perception (take for 0.5MPE); $\mathrm{f}$ - function of weakening (coefficient of «channeling») is taken as 0.05 . 
Table 4. The probability of occurrence of a damage «disease» from the action of welding aerosol substances (manganese and its compounds or hydrogen fluoride or nitrogen dioxide or iron oxide or carbon monoxide) in the presence of protection (gas mask).

\begin{tabular}{|c|c|c|c|c|}
\hline iron oxide & $\begin{array}{c}\text { manganese and its } \\
\text { compounds }\end{array}$ & hydrogen fluoride & nitrogen dioxide & carbon oxide \\
\hline 0.038925613 & 0.660608444 & - & 0.774474928 & - \\
\hline
\end{tabular}

$$
\mathrm{P}=1-(1-\mathrm{p} 1) *(1-\mathrm{p} 2) *(1-\mathrm{p} 4)=0.926438112
$$

Conclusion on option 2: the probability of disease from the action of manganese and its compounds or nitrogen dioxide in the presence of protection (gas mask) by the end of the working cycle of 1 hour 30 minutes of the work is about $92.6 \%$ (Fig. 3).

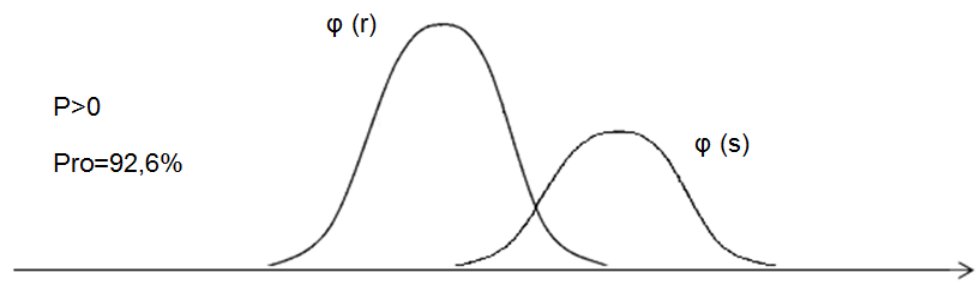

Fig. 3. The first damage when the outcome of the availability of protection.

Option 3:

Calculation of the probability of the second damage (death): protection (gas mask) is absent (attenuation function $\mathrm{f}=1$ ). We calculate the parametric safety margin $(\mathrm{U})$ and express through it the $\mathrm{p}$ - real variables - probabilities of outcomes:

$$
\begin{gathered}
\mathrm{U} 1=(\mathrm{S} 1-\mathrm{CEL} 1) /(\mathrm{S} 12+\mathrm{r} 2) 0.5, \quad \mathrm{U} 2=(\mathrm{S} 2-\mathrm{CEL} 2) /(\mathrm{S} 22+\mathrm{r} 2) 0.5, \\
\mathrm{U} 3=(\mathrm{S} 3-\mathrm{CEL} 3) /(\mathrm{S} 32+\mathrm{r} 2) 0.5, \quad \mathrm{U} 4=(\mathrm{S} 4-\mathrm{CEL} 4) /(\mathrm{S} 42+\mathrm{r} 2) 0.5, \\
\mathrm{U} 5=(\mathrm{S} 5-\mathrm{CEL} 5) /(\mathrm{S} 52+\mathrm{r} 2) 0.5,
\end{gathered}
$$

where S1 - criterion parametric effects (for the onset of the damage when exposed to iron oxide), CEL1 - missing (this variable from further calculations exclude); S2 - criterion parametric effects (for the onset of the damage when exposed to manganese and its compounds), CEL2 - 500; S3 - criterion parametric effects (for the onset of the damage when exposed to hydrogen fluoride), CEL3 - 1500; S4 - criterion parametric effects (for the onset of the damage when exposed to nitrogen dioxide), CEL4 - 37.6; S5 - criterion parametric effects (for the onset of the damage when exposed to carbon monoxide), CEL5 $3400 ; \mathrm{r}$ - perception (take for 0.5CEL).

Table 5. The probability of occurrence of the damage «death» from the action of welding aerosol substances (manganese and its compounds or hydrogen fluoride or nitrogen dioxide or iron oxide) in the absence of protection (gas mask).

\begin{tabular}{|c|c|c|c|}
\hline $\begin{array}{c}\text { manganese and its } \\
\text { compounds }\end{array}$ & hydrogen fluoride & nitrogen dioxide & carbon oxide \\
\hline- & - & 0.888591617 & - \\
\hline
\end{tabular}




$$
\mathrm{P}=1-(1-\mathrm{p} 4)=0.888591617
$$

Conclusion on option 3:

The probability of the second damage (death) from exposure to unprotected nitrogen dioxide (gas mask) by the end of the working cycle of 1 hour 30 minutes of the work is about $88.9 \%$ (Fig. 4).

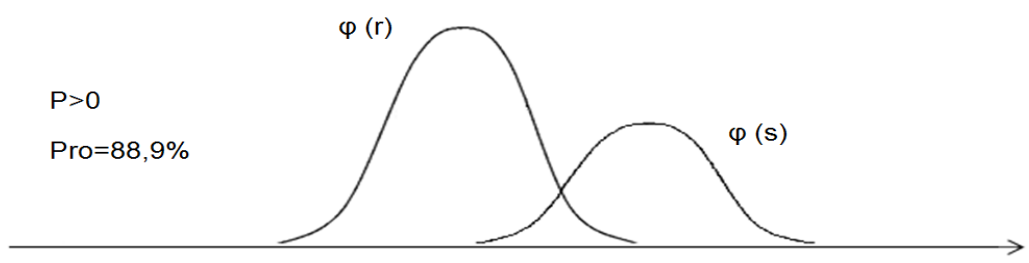

Fig. 4. The second damage when the outcome of the lack of protection.

Option 4:

Calculation of the probability of the second damage (death): there is a protection (gas mask). We calculate the parametric safety margin (U) and express through it the $\mathrm{p}-$ real variables - probabilities of outcomes:

$$
\begin{gathered}
\mathrm{U} 1=(\mathrm{S} 1-\mathrm{CEL} 1) /(\mathrm{S} 12+\mathrm{r} 2) 0.5, \quad \mathrm{U} 2=(\mathrm{S} 2-\mathrm{CEL} 2) /(\mathrm{S} 22+\mathrm{r} 2) 0.5, \\
\mathrm{U} 3=(\mathrm{S} 3-\mathrm{CEL} 3) /(\mathrm{S} 32+\mathrm{r} 2) 0.5, \quad \mathrm{U} 4=(\mathrm{S} 4-\mathrm{CEL} 4) /(\mathrm{S} 42+\mathrm{r} 2) 0.5, \\
\mathrm{U} 5=(\mathrm{S} 5-\mathrm{CEL} 5) /(\mathrm{S} 52+\mathrm{r} 2) 0.5,
\end{gathered}
$$

where S1 - criterion parametric effects (for the onset of the damage when exposed to iron oxide), CEL1 - missing (this variable from further calculations exclude); S2 - criterion parametric effects (for the onset of the damage when exposed to manganese and its compounds), CEL2 - 500; S3 - criterion parametric effects (for the onset of the damage when exposed to hydrogen fluoride), CEL3 - 1500; S4 - criterion parametric effects (for the onset of the damage when exposed to nitrogen dioxide), CEL4 - 37.6; S5 - criterion parametric effects (for the onset of the damage when exposed to carbon monoxide), CEL5 3400; the function of weakening (coefficient «breakthrough»), $\mathrm{f}=0,05$.

Conclusion on option 4:

Calculation of probability of occurrence of the damage (death) in the simulated situation in the presence of protection (gas mask) by the end of the working cycle of 1 hour 30 minutes of the work on the received data we consider inexpedient $(\mathrm{S}<\mathrm{CEL}$ ) (Fig. 5).

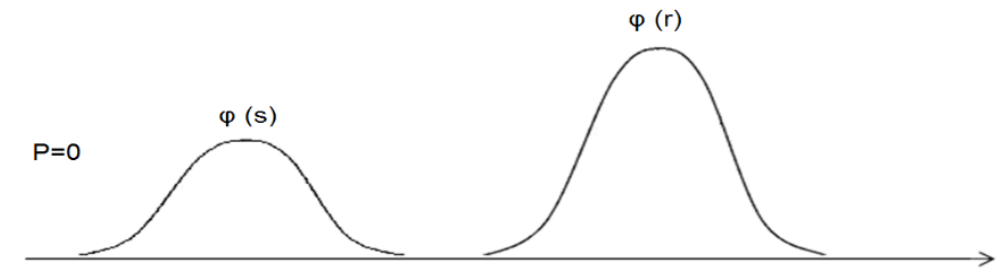

Fig. 5. The second damage in the presence of protection. 


\section{Conclusion}

The study of the probability of the presented local technogenic hazards of the industrial zone of the megalopolis is purely theoretical and does not pretend to the description of the real industrial facility.

In the construction of a linguistic model for the implementation of the damage from the position of extreme pessimism, the situation of emergency ventilation shut-off during the work of personnel in difficult conditions was simulated. Taking into account the existing prerequisites for the implementation of the damage, its logical-parametric model was built.

When calculating the probability of implementation in a simulated situation, the first damage (toxic effects - disease) were established the risk values of $99.9 \%$ and $92.6 \%$ for the absence and the presence of protection (gas mask), respectively; in the calculation of the second damage (the toxic effect is death) from exposure to nitrogen dioxide without protection (mask) by the end of operating cycle 1 hour 30 minutes a clean work is about $88.9 \%$; in the presence of protection - in view of inexpediency of definition of probability function the logic of application of possibility (fuzzy) function of incident is proved.

\section{References}

1. O.V. Denisov, Yu.I. Bulygin, A.E. Ponomarev, I.A. Ponomareva, V.V. Lebedeva, Innovative solutions shockproof protection in occupations associated with an increased risk of injury. IOP Conf. Ser.: Earth and Envir. Scie.: Curr. Prob. and Solut. «Ecology and Safety in the Technosphere: Current Problems and Solutions», p. 012044 (2017)

2. O. Denisov, M. Pleshko, V. Merenyashev, I. Ponomareva, Scale factor management in the studies of affine models of shockproof garment elements. E3S Web of Conf. «High-Rise Constr. HRC 2017», 3068 (2017)

3. A.A. Kozlova, A.V., Vestnik AnGTU. № 9, p. 214-218 (2015)

4. D.A. Kuznetsov, A.S. Smolina et al., Vestnik PNIPU, 16, № 2, pp. 21-34 (2014)

5. Marganets $i$ ego soedineniya. Assistent diagnostiki: Spravochnik [ER] http://www.rihtop.ru/diagnoseassistant/ Substance.aspx?id=70.

6. N.I. Muminova, Abdurahmanov E., Muradova D.K., Yunusova, Eur. Res., № 10, pp. 16-18 (2015) 